Revista Água Viva

ISSN 1678-7471

\title{
JORNAL DO CONHECIMENTO: GÊNEROS JORNALÍSTICOS E ENSINO DE LÍNGUA MATERNA
}

\section{JORNAL DO CONHECIMENTO: JORNALISTIC GENRES AND MOTHER LANGUAGE TEACHING}

\author{
Ana Maria de Sousa ${ }^{1}$ \\ Elaine Maria Luz Barbosa ${ }^{2}$ \\ Juscelino Francisco do Nascimento ${ }^{3}$
}

Recebido em: 02 mai. 2020.

Aceito em: 26 jul. 2020.

DOI 10.26512/aguaviva.v5i3.31304

RESUMO: Neste artigo, apresentamos um relato de experiência acerca do planejamento e da realização de oficinas de produção textual, na esfera dos gêneros jornalísticos, desenvolvidas no âmbito do Programa Institucional de Bolsa de Iniciação à Docência (PIBID), do Curso de Letras/Português da Universidade Federal do Piauí (UFPI), Campus Senador Helvídio Nunes de Barros, em Picos - PI. As atividades foram realizadas por meio de oficinas com os alunos dos $1^{\circ}, 2^{\circ}$ e $3^{\circ}$ anos do Ensino Médio, os quais promoveram a produção e a criação do Jornal do Conhecimento do Centro Estadual de Tempo Integral (CETI) Marcos Parente. Objetivamos, pois, a) relatar a nossa experiência durante o período de atuação e desenvolvimento do jornal escolar; b) abordar o trabalho com gêneros textuais na escola; e c) refletir sobre as contribuições dessas atividades para o processo de ensino-aprendizagem dos alunos. Para a materialização desta proposta, foi feita, inicialmente, uma pesquisa bibliográfica, fundamentada nos embasamentos teóricos de Bakhtin (2003), Marcuschi (2005), Traquina (2005), Lage (2001, 2005), entre outros. Em seguida, foram realizadas as oficinas acerca dos gêneros jornalísticos. Evidenciamos que a prática de atividades voltadas para tais gêneros motivou o desenvolvimento

\footnotetext{
${ }^{1}$ Graduanda do Curso de Licenciatura em Letras/Português pela Universidade Federal do Piauí (UFPI), Campus Senador Helvídio Nunes de Barros (CSHNB), em Picos - PI. E-mail: ana-maria-456@ hotmail.com

${ }^{2}$ Jornalista, graduada pela Universidade Federal do Piauí (UFPI). Graduanda do Curso de Licenciatura em Letras/Português pela Universidade Federal do Piauí (UFPI), Campus Senador Helvídio Nunes de Barros (CSHNB), em Picos - PI. Especialista em Assessoria de Comunicação e Jornalismo Digital pelo Instituto de Educação Superior Raimundo Sá (IERSA). E-mail: elaineluzb@ gmail.com

${ }^{3}$ Doutor em Linguística pela Universidade de Brasília (UnB), Graduado e Mestre em Letras pela Universidade Federal do Piauí (UFPI), da qual é Professor Adjunto e Coordenador do Curso de Letras/Português, no Campus Senador Helvídio Nunes de Barros. Professor Formador do Centro de Educação Aberta e a Distância (CEAD/UFPI), onde é Coordenador de Estágios do Curso de Letras/Inglês e professor colaborador do Programa de Pós-graduação em Formação de Professores, da Universidade Estadual da Paraíba (UEPB). E-mail: juscelinosampa@hotmail.com
} 
da leitura e da escrita dos alunos, de modo que essas ações funcionaram como instrumento de interação dos discentes em sua vivência escolar.

Palavras-chave: Gêneros Textuais. Gêneros Jornalísticos. Jornal do Conhecimento.

\begin{abstract}
In this paper, we present an experience report about the planning and implementation of textual production workshops, in the sphere of journalistic genres, developed within the Programa Institucional de Bolsa de Iniciação à Docência (PIBID), of the Course of Letters/Portuguese at the Federal University of Piauí (UFPI), Campus Senador Helvídio Nunes de Barros, in Picos - PI. The activities were carried out through workshops with students of the 1st, 2nd and 3rd years of high school, which promoted the production and creation of the Jornal do Conhecimento from the Centro Estadual de Tempo Integral (CETI) Marcos Parente. We therefore aim at: a) report our experience during the period of activity and development of the school newspaper; b) address the work with textual genres at school; and c) reflect on the contributions of these activities to the students' teaching-learning process. For the materialization of this proposal, a bibliographical research was initially made, based on the theoretical foundations of Bakhtin (2003), Marcuschi (2005), Traquina (2005), Lage (2001, 2005), among others. Then, workshops on journalistic genres were held. We evidenced that the practice of activities focused on these genres motivated the development of the reading and writing of the students, so that these actions worked as an instrument of interaction of the students in their school experience.
\end{abstract}

Keywords: Textual Genres. Journalistic genres. Jornal do Conhecimento.

\title{
1. INTRODUÇÃO
}

Neste trabalho, apresentamos um relato de experiência sobre a realização de oficinas de produção textual com base nos gêneros jornalísticos, por meio de práticas e atividades que resultaram no planejamento, produção e criação do Jornal do Conhecimento do Centro Estadual de Tempo Integral (CETI) Marcos Parente.

As atividades foram feitas no âmbito do Programa Institucional de Bolsa de Iniciação à Docência (PIBID), do Curso de Letras/Português, da Universidade Federal do Piaúi (UFPI), Campus Senador Helvídio Nunes de Barros, em Picos - PI, projeto do Governo Federal financiado pela Coordenação de Aperfeiçoamento de Pessoal de Nível Superior (Capes).

As oficinas de produção textual, com base em gêneros jornalísticos, surgiram a partir da necessidade de estimular e desenvolver o hábito da leitura nos alunos, contribuindo, assim, para a melhoria da escrita e interpretação textual. Além disso, destaca-se a importância de 
oportunizar aos alunos o contato com outros gêneros textuais, não só com aqueles próprios do ambiente escolar.

A proposta de trabalhar com tais gêneros decorre do fato de eles apresentarem uma linguagem simples e direta, além de promoverem uma interação social entre as pessoas. Dessa forma, a oficina se estabelece como uma ferramenta eficaz, facilitadora e motivadora no processo de aprendizagem e desenvolvimento da prática de produção textual a partir do contato com os textos que circulam na mídia jornalística.

Neste artigo, visamos apresentar e relatar a experiência de monitoria no PIBID por meio da realização de oficinas com os alunos dos $1^{\circ}, 2^{\circ}$ e $3^{\circ}$ Anos do Ensino Médio, durante os meses de maio e julho de 2019, sobre os gêneros jornalísticos, o que resultou na produção do jornal escolar, intitulado Jornal do Conhecimento.

Para a realização do trabalho, embasamo-nos nos pressupostos teóricos de Bakhtin (2003), Marcuschi (2005), Traquina (2005) e Lage (2001, 2005), entre outros.

Objetivamos, com este trabalho, a) relatar a nossa experiência durante o período de atuação e desenvolvimento do jornal escolar; b) abordar o trabalho com gêneros textuais na escola; e c) refletir sobre as contribuições dessas atividades para o processo de ensinoaprendizagem dos alunos.

Por fim, evidenciamos, com a realização das oficinas e seus desdobramentos, que a prática de atividades voltadas para os gêneros jornalísticos motivou o desenvolvimento da leitura e da escrita dos alunos, de modo que essas ações funcionaram como instrumento de interação dos discentes em sua vivência escolar.

\section{Procedimentos metodológicos}

Para a materialização desta proposta, foi feita, inicialmente, uma pesquisa bibliográfica, fundamentada nos embasamentos teóricos de Bakhtin (2003), Marcuschi (2005), Traquina (2005), Lage (2001, 2005), entre outros. Em seguida, foram realizadas oficinas sobre os gêneros jornalísticos, feitas por meio de aulas expositivas e uso de recursos como slides, e atividades práticas de treinamento do conteúdo trabalhado, a fim de que os alunos se familiarizassem com os gêneros e desenvolvessem suas escritas.

Entendemos por estudo bibliográfico uma pesquisa na literatura de autores que trabalham com teorias que orientam a produção científica, de modo que esses autores servirão de base teórica para o novo trabalho. Essa revisão bibliográfica pode ser realizada em várias 
fontes, como livros, artigos, revistas, na internet, entre outras. Nessa direção, consoante Boccato (2006, p. 266):

[...] a pesquisa bibliográfica busca a resolução de um problema (hipótese) por meio de referenciais teóricos publicados, analisando e discutindo as várias contribuições científicas. Esse tipo de pesquisa trará subsídios para o conhecimento sobre o que foi pesquisado, como e sob que enfoque e/ou perspectivas foi tratado o assunto apresentado na literatura científica (BOCCATO, 2006, p. 266).

Depois de nos apropriarmos daquilo que a literatura trata acerca do nosso objeto de estudo, realizamos cinco oficinas, nas salas de multimídias do CETI Marcos Parente, em momentos distintos, entre os meses de maio e junho de 2019. No mês de julho do mesmo ano, detivemo-nos à organização das produções realizadas pelos alunos e à diagramação do jornal, para posterior impressão e divulgação.

Nas oficinas, foram trabalhados diversos gêneros do domínio discursivo jornalístico (BAZERMAN, 2006), mas, para facilitar o aprendizado das turmas, restringimo-nos, nesse primeiro momento, ao artigo de opinião, à entrevista jornalística e à notícia.

Depois das explicações e exemplificações, propusemos aos discentes uma atividade que consistia na produção de cada um dos gêneros estudados. Para isso, as turmas foram divididas em três grupos, os quais elaboraram, com nosso apoio, o que lhes fora requerido.

\section{Os gêneros textuais}

A classificação específica dos textos de acordo com sua tipologia surge na Grécia Antiga Clássica, quando Aristóteles estabelece três categorias fundamentais de gênero: o lírico, o épico e o dramático. Essa classificação desenvolvida pelo filósofo foi a base fundamental para a representação das categorias presentes na atualidade.

A abordagem dos gêneros textuais no campo da linguística, contudo, só ganha a devida notoriedade a partir do século XX, por meio de estudos aprofundados da linguagem como uma atividade interativa e dialógica. Bakhtin, ao trabalhar com a natureza social e ideológica da linguagem, acredita que a interação e a prática social dão origem à enunciação, na qual cada contexto é que determina as características do gênero que deverá ser utilizado. Dessa forma, o autor reforça a existência da diversidade de gêneros, conceituando-os como "tipos relativamente estáveis de enunciados" (BAKHTIN, 2003, p. 262). 
A linguagem é um meio eficaz de comunicação e é definida por Fiorin como "a capacidade específica da espécie humana de se comunicar por meio de signos” (20013, p. 31). Nas nossas práticas cotidianas de linguagem, os gêneros textuais surgem de acordo com a necessidade de comunicação - que são ilimitadas - e, por essa razão, eles são incontáveis, posto que, conforme Swales (1990, p. 46), “os gêneros discursivos são veículos de comunicação para atingir um objetivo".

Nas nossas interações diárias, é necessário o constante ato de fazer leituras, ação fundamental para o entendimento dos discursos. A leitura, para Brandão e Micheletti (2002, p. 09) é compreendida como:

[...] um processo abrangente e complexo; é um processo de compreensão, de intelecção de mundo que envolve uma característica essencial e singular ao homem: a sua capacidade simbólica e de interação com o outro pela mediação de palavras. $\mathrm{O}$ ato de ler não pode se caracterizar como uma atividade passiva (BRANDÃO, MICHELETTI, 2002, p. 09).

Esse processo se faz mais complexo e técnico quando os discursos são escritos, pois, nesse contexto, não será possível contar com outros recursos, a não ser com a própria habilidade de leitura e familiaridade com os gêneros textuais. Com isso, é possível observar a importância da leitura no processo educativo, como também a necessidade de se trabalhar os mais variados gêneros.

Como sabemos, a escola tem o papel de formar cidadãos para atuarem na sociedade. Para isso, os conteúdos da grade curricular devem estar em consonância com o papel social da instituição e, ainda, com as exigências externas do seu público, sobretudo no que diz respeito às suas necessidades comunicativas, nas quais se utilizam diferentes gêneros textuais. Dessa forma, é necessário trabalhar conteúdos relacionados à comunicação que tenham uma aplicação não só direta nas atividades avaliativas, mas que possam possibilitar, aos alunos, conhecimentos para atuarem em outros contextos, como preconizam os Parâmetros Curriculares Nacionais para o Ensino Médio (2000, p. 22):

A escola não pode garantir o uso da linguagem fora de seu espaço, mas deve garantir tal exercício de uso amplo no seu espaço, como forma de instrumentalizar o aluno para seu desempenho social. Armá-lo para poder 
competir em situação de igualdade com aqueles que julgam ter o domínio social da língua.

Nosso trabalho, pois, será positivo no sentido de que os alunos terão um conhecimento possível de ser colocado em prática no dia a dia, assim como desenvolverão suas habilidades de leitura e escrita. Dessa forma, vemos como é importante o ensino dos diversos gêneros textuais, já que:

Os textos organizam-se sempre dentro de certas restrições de natureza temática, composicional e estilística, que os caracterizam como pertencentes a este ou aquele gênero. Desse modo, a noção de gênero, constitutiva do texto, precisa ser tomada como objeto de ensino. (PCN EF, 1998, p. 23). [...] Nessa perspectiva, é necessário contemplar, nas atividades de ensino, a diversidade de textos e gêneros, e não apenas em função de sua relevância social, mas também pelo fato de que textos pertencentes a diferentes gêneros são organizados de diferentes formas. (PCN EF, 1998, p. 23).

Há apenas cinco tipos textuais: dissertativos, narrativos, descritivos, expositivos e injuntivos, ao passo que existem infinitos gêneros textuais, os quais podem, inclusive, mesclarse entre si. Embora infinitos, o conhecimento sobre eles é imprescindível, pois, assim, é possível identificá-los e distingui-los, uma vez que, como afirma Marcuschi (2005, p. 31), "não [se] deve trazer dificuldade interpretativa, já que o domínio da função supera a forma na determinação do gênero, o que evidencia a plasticidade e a dinamicidade dos gêneros".

Além do que foi citado sobre a importância, influência, uso e dinamicidade dos gêneros textuais, esses ainda são importantes no ensino de Língua Portuguesa, pois, na escola, conforme Schneuwly e Dolz (2004, p. 51), "eles constituem o instrumento de mediação de toda a estratégia de ensino e o material de trabalho, necessário e inesgotável, para o ensino da textualidade".

\subsection{Gêneros jornalísticos e ensino de língua materna}

No tocante ao estudo dos gêneros textuais, a abordagem do gênero jornalístico nas escolas constitui-se como um importante aparato para estimular o hábito da leitura e para desenvolver e aperfeiçoar o processo da escrita. 
A mídia jornalística, por meio de seus diversos gêneros textuais, como a notícia, a reportagem, o artigo de opinião e a crônica, retrata de forma real e atual o cotidiano através de uma linguagem simples, que traz a novidade de maneira direta e acessível. De acordo com Traquina (2005, p. 22), o jornalismo "é uma atividade criativa, plenamente demonstrada, de forma periódica, pela invenção de novas palavras e pela construção do mundo em notícias [...]”.

Por apresentar essa diversidade e por trazer a presença da linguagem verbal e não verbal, com a presença de figuras e gráficos, os gêneros jornalísticos enriquecem o conhecimento dos alunos e contribuem para o desenvolvimento da leitura, da escrita e do posicionamento crítico frente à realidade.

Faria aponta que trabalhar esses gêneros nas escolas traz inúmeras contribuições tanto para os alunos quanto para os professores:

Para os alunos o jornal: - é o mediador entre a escola e o mundo; - ajuda a relacionar seus conhecimentos prévios e sua experiência pessoal de vida com as notícias; - leva-os a formar novos conceitos e a adquirir novos conhecimentos a partir de sua leitura; - ensina-os a aprender a pensar de modo crítico sobre o que lê; - estabelece novos objetivos de leitura. Para os professores, enfim, o jornal é um excelente material pedagógico (para todas as áreas) sempre atualizado, desafiando- os a encontrar o melhor caminho didático para usar esse material na sala de aula (FARIA, 2008, p. 12).

Ao trabalhar o gênero jornalístico em sala de aula, entende-se que o jornal impresso, por exemplo, se estabelece como um formato dinâmico para a aprendizagem da Língua Portuguesa, e possibilita o contato com uma significativa quantidade de gêneros, uma maior interação entre os alunos e a escola, e, ainda, desenvolve as habilidades de leitura, observação, interpretação e produção criativa.

A partir dessa perspectiva, os gêneros notícia, entrevista e artigo de opinião, por nós trabalhados, são bastante úteis no ensino de língua materna, desde que bem trabalhados em sala de aula. A notícia expressa sempre um fato novo, sendo, portanto, caracterizada pela contemporaneidade e aproximação com o tempo e o espaço dos acontecimentos. Ela é "o relato de uma série de fatos a partir do fato mais importante ou interessante; e de cada fato, a partir do aspecto mais importante ou interessante" (LAGE, 2005, p. 16). 
A entrevista jornalística, por sua vez, possibilita a produção textual por meio do modelo pergunta-resposta, e envolve a obtenção de informações por meio de um roteiro de planejamento e aplicação de questionários, que permitem uma interação face a face com aquele a quem se entrevista. De acordo com Lage (2001, p. 32), a “[...] entrevista é o procedimento clássico de apuração de informações em jornalismo. É uma expansão da consulta às fontes, objetivando, geralmente, a coleta de interpretações e a reconstituição de fatos".

Por fim, o artigo de opinião "[...] é um gênero jornalístico argumentativo escrito, publicado em jornais, revistas, internet, e sempre assinado. A assinatura identifica o autor, o responsável pela opinião" (GAGLIARDI, AMARAL, 2004, p. 57). Caracteriza-se como um texto dissertativo-argumentativo em que o autor apresenta um tema e procura defender sua opinião por meio da argumentação, sendo importante para a liberdade de expressão do ponto de vista dos alunos, para o uso do raciocínio crítico e da linguagem persuasiva.

Os textos jornalísticos, desse modo, apresentam categorias, características e estruturas específicas que se inter-relacionam diretamente com o interlocutor por meio dos sentidos presentes em cada enunciado, como afirma Bakhtin (2003) e Silva, Souza-Dias e Nascimento (2019) sobre as inter-relações dinâmicas que determinam a índole do texto.

Utilizar esses gêneros nas escolas permite, pois, que os alunos também participem dos acontecimentos referentes ao ambiente escolar, reconheçam e explorem todos os assuntos que dizem respeito à sua realidade, de modo a interagir com os sujeitos sociais e descrever, de forma clara e concisa, suas vivências estudantis.

\section{Resultados: a produção do Jornal do Conhecimento}

O Jornal do Conhecimento foi concebido a partir de práticas e atividades feitas com base em oficinas de produção textual de gêneros jornalísticos no âmbito do Programa Institucional de Bolsa de Iniciação à Docência (PIBID), do Curso de Letras/Português da Universidade Federal do Piauí (UFPI), Campus Senador Helvídio Nunes de Barros, em Picos - PI.

Por meio de oficinas, ocorridas entre os meses de maio e julho de 2019, os alunos dos $1^{\circ}, 2^{\circ}$ e $3^{\circ}$ Anos do Ensino Médio do Centro Estadual de Tempo Integral (CETI) Marcos Parente promoveram a criação do jornal como uma edição comemorativa da escola. Assim, produziram notícias, entrevistas e artigos de opinião a respeito dos acontecimentos escolares, sob nossa supervisão enquanto membros do PIBID. Com relação à divulgação, o jornal foi apresentado durante o evento de comemoração dos 70 anos da escola supramencionada. 
O formato do Jornal do Conhecimento, cujo nome foi escolhido pelos alunos por meio de votação dentre outras sugestões dadas por eles mesmos, é de $21 \mathrm{~cm}$ de largura por $29,7 \mathrm{~cm}$ de altura, o que corresponde ao tamanho A4, em um total de 10 páginas. Seu planejamento gráfico foi pensado de acordo com o contexto dos alunos e da escola, para que a diagramação pudesse representar a identidade escolar.

A edição conta com cinco seções, denominadas na parte superior das páginas e que correspondem, respectivamente, aos artigos, às entrevistas, a um espaço cultural, às notícias e, por fim, a uma galeria. Cada página - exceto a capa e a galeria - contém a numeração e o nome do jornal, que fica na parte superior, e a logomarca da escola, que se encontra na parte inferior das páginas. Todos os textos foram dispostos em colunas, respeitando o formato do jornal impresso, e contam com fotografias e os devidos créditos. A seguir, apresentamos e explanamos cada seção Jornal. 


\section{Figura 1 - Capa do Jornal do Conhecimento, Edição Comemorativa}

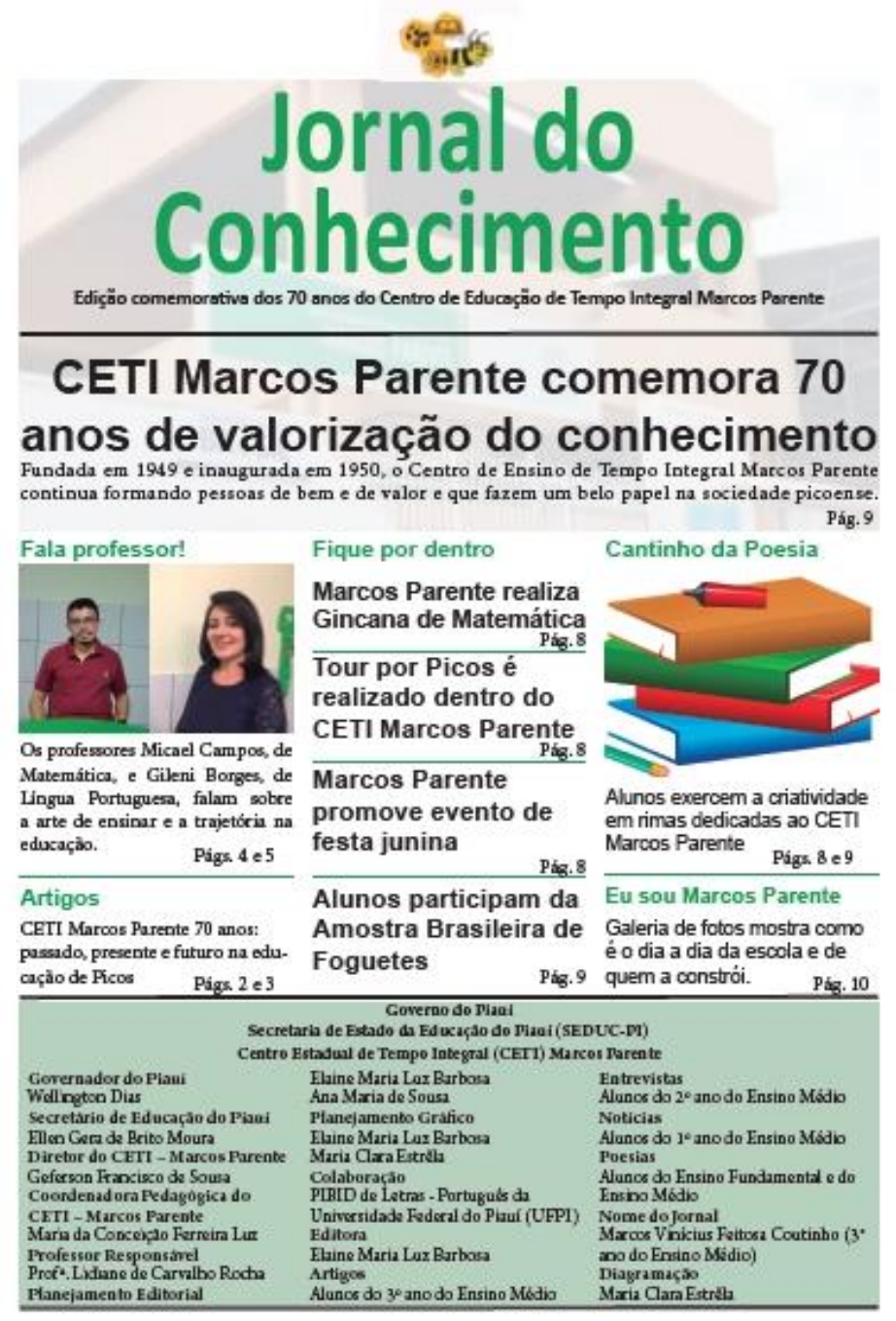

Fonte: Os autores (2019)

A capa, elemento unificador e interativo, consta na primeira página e contém a logomarca da escola na parte superior, o nome do jornal centralizado, em posição de destaque, e com um tamanho maior de fonte. Logo abaixo, está indicado que se trata de uma edição comemorativa dos 70 anos do CETI Marcos Parente. Há, também, as chamadas por editoria, a fim de convidar o leitor para a leitura das matérias que estão contidas no interior do jornal, por meio da indicação das páginas em que cada uma se encontra. Além disso, há o expediente do Jornal, com os dados da edição e listagem da equipe de produção com suas respectivas funções. 


\section{Figura 2 - Seção dos Artigos de Opinião do Jornal do Conhecimento}

2

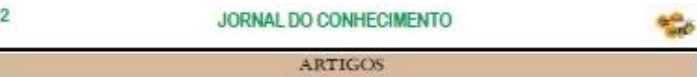

\section{A memória que o tempo não} perderá

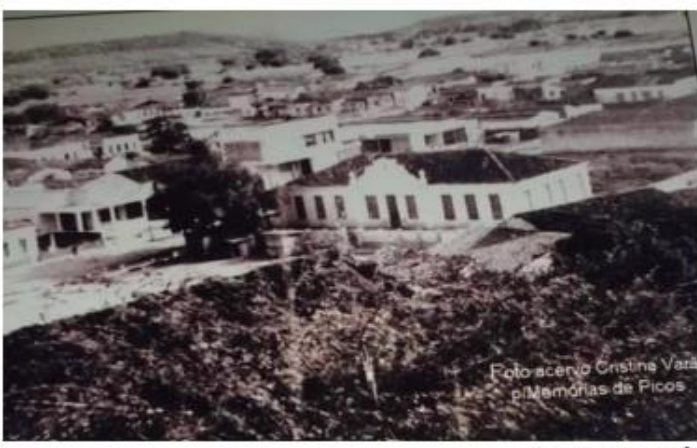

Maria Vitória Veloso (aluna do $3^{\circ}$ ano do Ensino Médio)

Marcos Parente, Centro de ginásio, até que comecou the dando a possibilidade de Ensino de Tempo Integral, a ser pensada em 1947 e aprender e se profissionalizar localizado no recinto da Rua inaugurada em 1948 com ao longo de toda a carreir Luiz Nunes, vem avançando o nome Ginassio Picoense. académica.

recursos de ensino e carreira lugares como, por exemplo, E perceptivel, portanto, profissional, todavia o que espaco do Museu Ozildo suas mehorias, garantindo muitos nấo sabem, pois não Albano, em seguida para qualdade de tem conhecimento a respeto onde atualmente e o Colegio a conquistarem suas metas. de sua ongem e dificuldades Coelho Rodrigues e, por fm, Assim. o Marcos Parente se por mias de dez anos que permanece até os dias aproxima dos setenta anos de muitas geraçôes e histórias Munical ia que o coverno Tendo como primeiro para contar, todos esses alegava näo ter condiçes de diretor Vidal de Freitas, a momentos sendo guardados manter a escola. cidade de Picos não possuia matriculando nossos jovens e

क्षेण

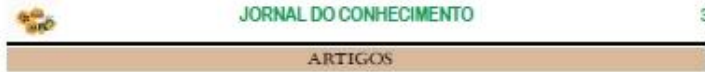

Do Ginásio ao CETI: 70 anos

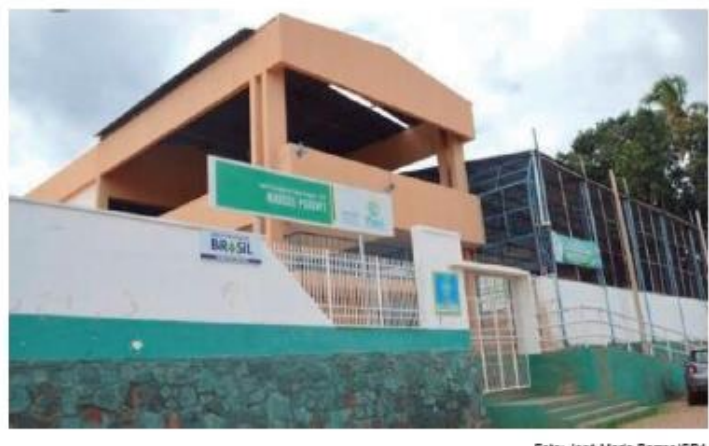

Mickelry STC e M. Vitor Feitosa (alunos do $3^{\circ}$ ano do Ensino Médio)

o Colégio Marcos Parente ser uma das primeiras diversas ideias, porém, a que teve sua inauguraçá no escolas de tempo integral the chamou atençán foi a nome de Ginásio Picoense, sido o primeino inísio da para a mocidan de Picos

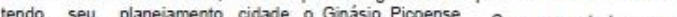
realizado no governo de atualmente chamadode CETI Com uma estrutura grande Celso Eulálio juntamente Marcos Parente teve ativa e bem planejada, suporta com o Vidal de Freitas que participaçá na formaçáa como escola de tempo vina a se tornar seu primeiro dos primeiros funcionarios integral, oferece nove aulas diretor. Formou varios do municipio (termo usado diárias e três refeicóes a cidadáos importantes, sendo na epoca). longo do dia. O CETI das menthores escolas da $\theta^{\circ} O$ Ginásio Picoense surgiu Marcos Parente é bastante das melhores escolas da por meio da política, pois o procurado pelos pais por Tornouse pionein prefeitoeleitoem 1049quenia sua excelente repulaça por Tornou-se pioneira na deixar algo que marcasse tambem por oferecer Um
educaçâo picoense por sua candidatura, aparecendo ensino integral de qualidade. क्षिए

Fonte: Os autores (2019)

Os artigos de opinião, redigidos pelos alunos do $3^{\circ}$ Ano, estão na seção intitulada Artigos, localizados nas páginas 2 e 3 do jornal, logo após a capa. Os textos trazem a opinião dos estudantes e contribuem para desenvolver as habilidades de argumentação e exposição, além de fazer uma abordagem histórica do CETI Marcos Parente desde o período de inauguração até os dias atuais. 
Figura 3 - Seção das Entrevistas do Jornal do Conhecimento

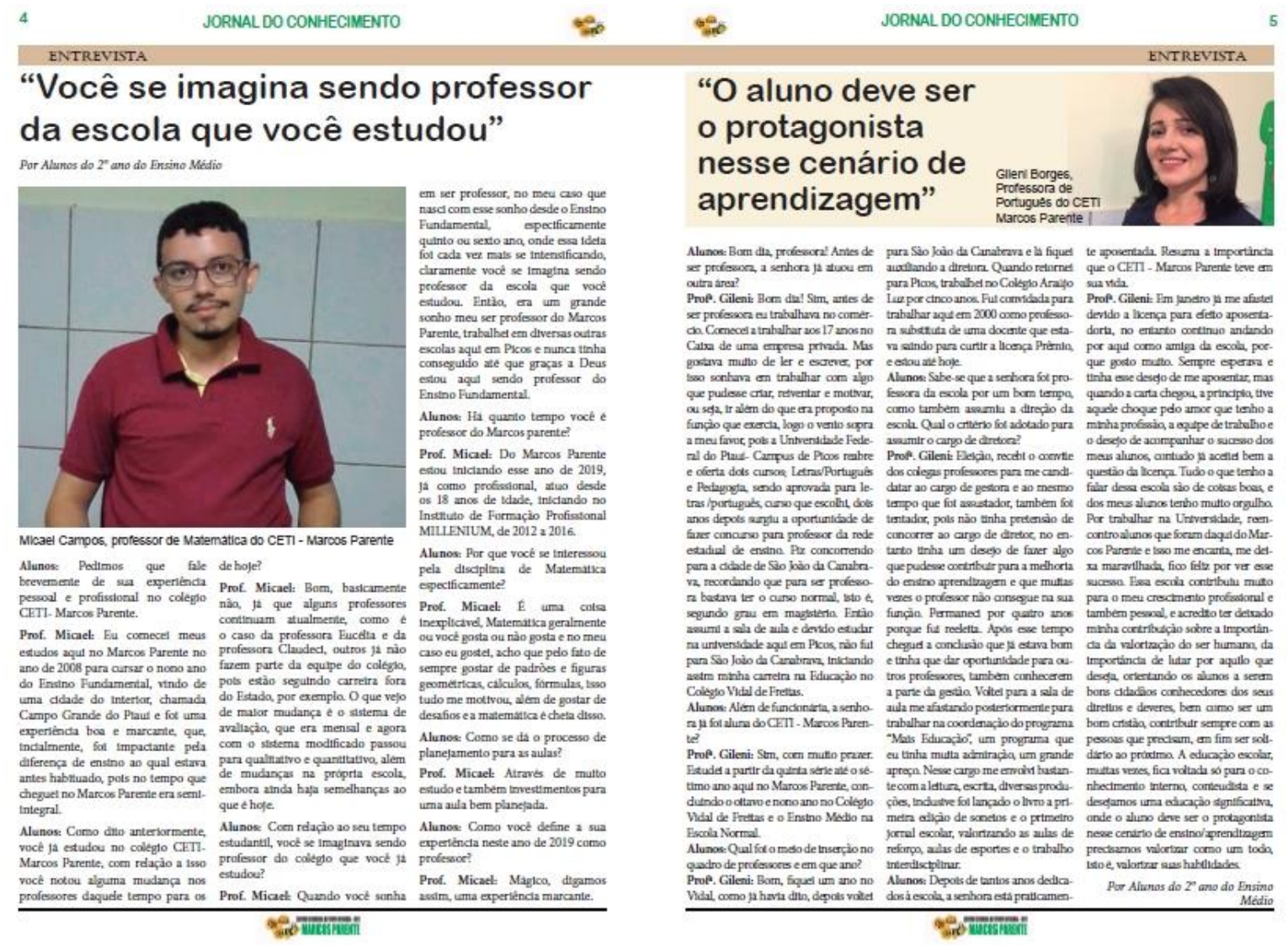

Fonte: Os autores (2019)

A seção seguinte - Entrevista - está presente nas páginas 4 e 5 do Jornal e traz as entrevistas que foram organizadas no formato pergunta-resposta. Este espaço foi criado e produzido pelos alunos do $2^{\circ}$ Ano do e contém as respostas de duas personalidades, o professor de Matemática e a professora de Português, sobre suas trajetórias profissionais e, principalmente, sobre suas atuações na escola. 
Figura 4 - Cantinho da Poesia do Jornal do Conhecimento

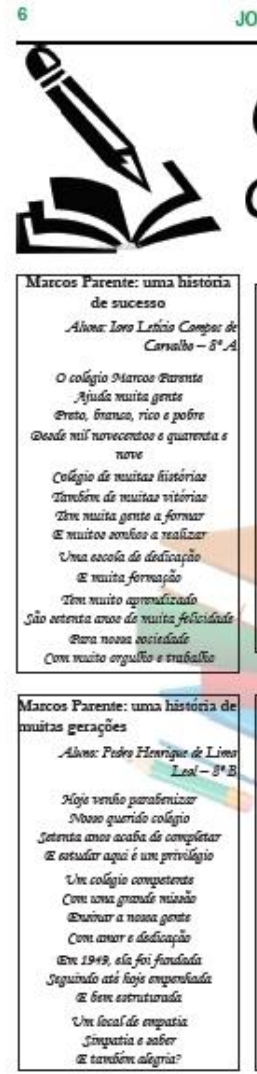

JONAL DO CONHECIMENTO

\section{Cantinho} da poesia

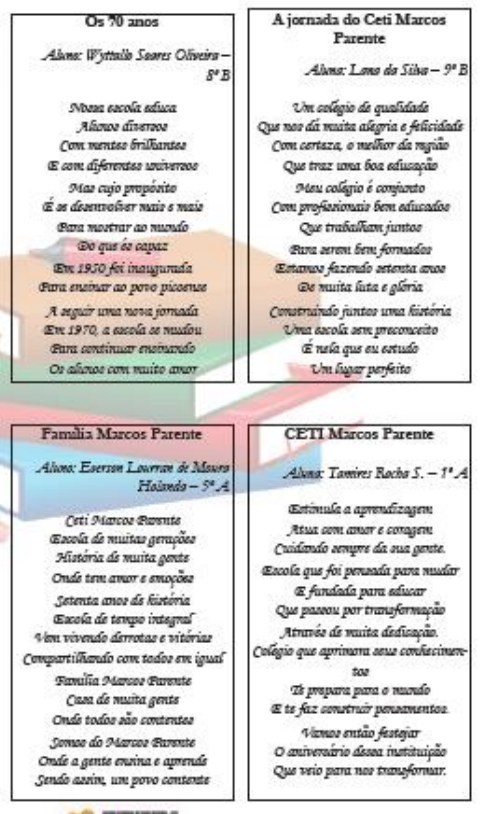

*e
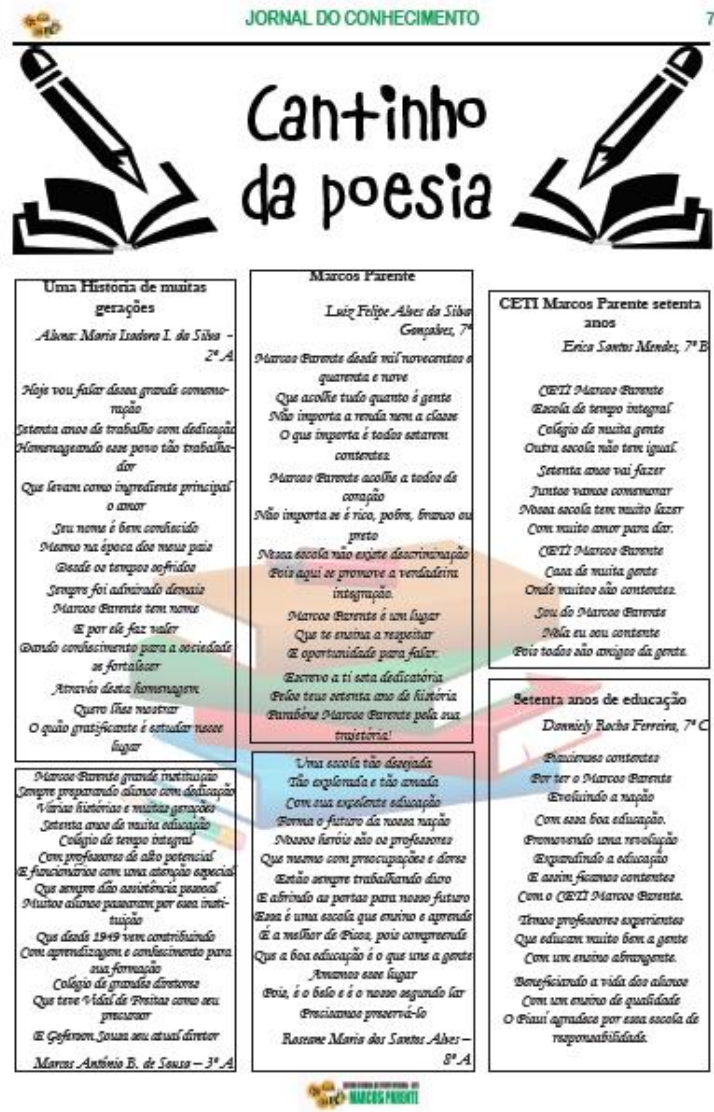

Fonte: Os autores (2019)

Este é um espaço pensado para a organização, disposição e publicação das produções culturais da escola. A seção específica que recebeu o nome, nesta edição, de Cantinho da Poesia, reúne uma série de poemas compostos pelos alunos dos Ensinos Fundamental e Médio. As produções foram feitas durante a execução de um projeto literário da escola. Dessa forma, esse espaço específico do Jornal serviu como meio de divulgação do trabalho literário desenvolvido pelos alunos. 
Figura 5 - Seção das Notícias do Jornal do Conhecimento
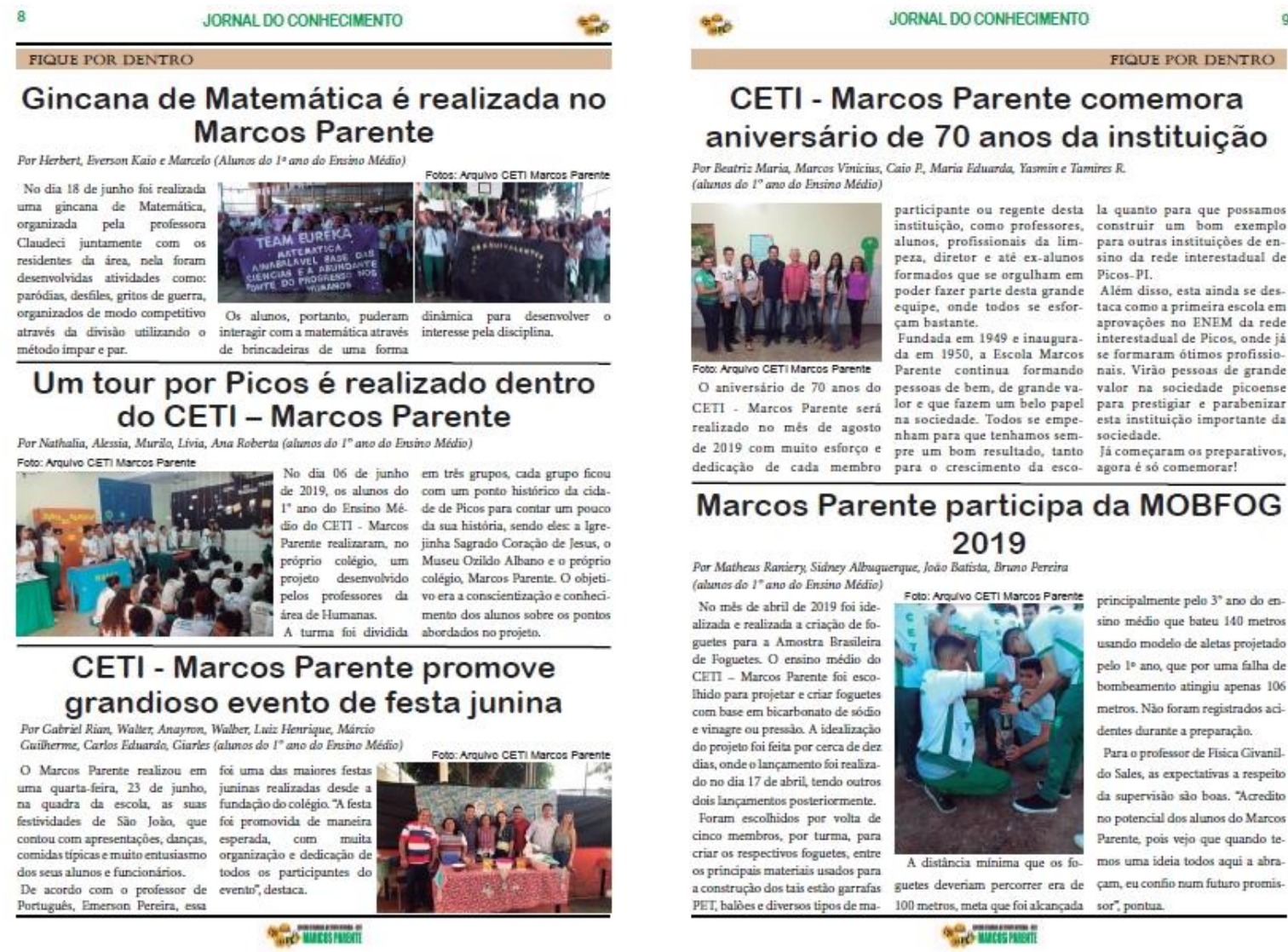

Fonte: Os autores (2019)

A seção das notícias recebe o nome de Fique por Dentro e está localizada nas páginas 8 e 9 do jornal. O espaço conta, ao todo, com cinco notícias, redigidas pelos alunos do $1^{\circ}$ Ano, os quais apresentam acontecimentos que fazem parte do cotidiano dos estudantes, já que ocorreram no ambiente escolar.

Na seção, os alunos tiveram a oportunidade de se apropriar do principal gênero textual do gênero jornalístico, o que lhes possibilitou a experiência com o discurso midiático, pois as notícias seguem a estrutura convencional de uma notícia com a presença do título, que tem como objetivo atrair o leitor para a leitura do texto; o lide jornalístico, correspondente ao primeiro parágrafo e que responde as seis perguntas básicas: O que? Quem? Quando? Onde? Como? Por que?; e o corpo da notícia, que diz respeito aos demais parágrafos do texto, fornecendo ao leitor as informações em ordem cronológica ou de importância. 


\section{Figura 6 - Galeria do Jornal do Conhecimento}

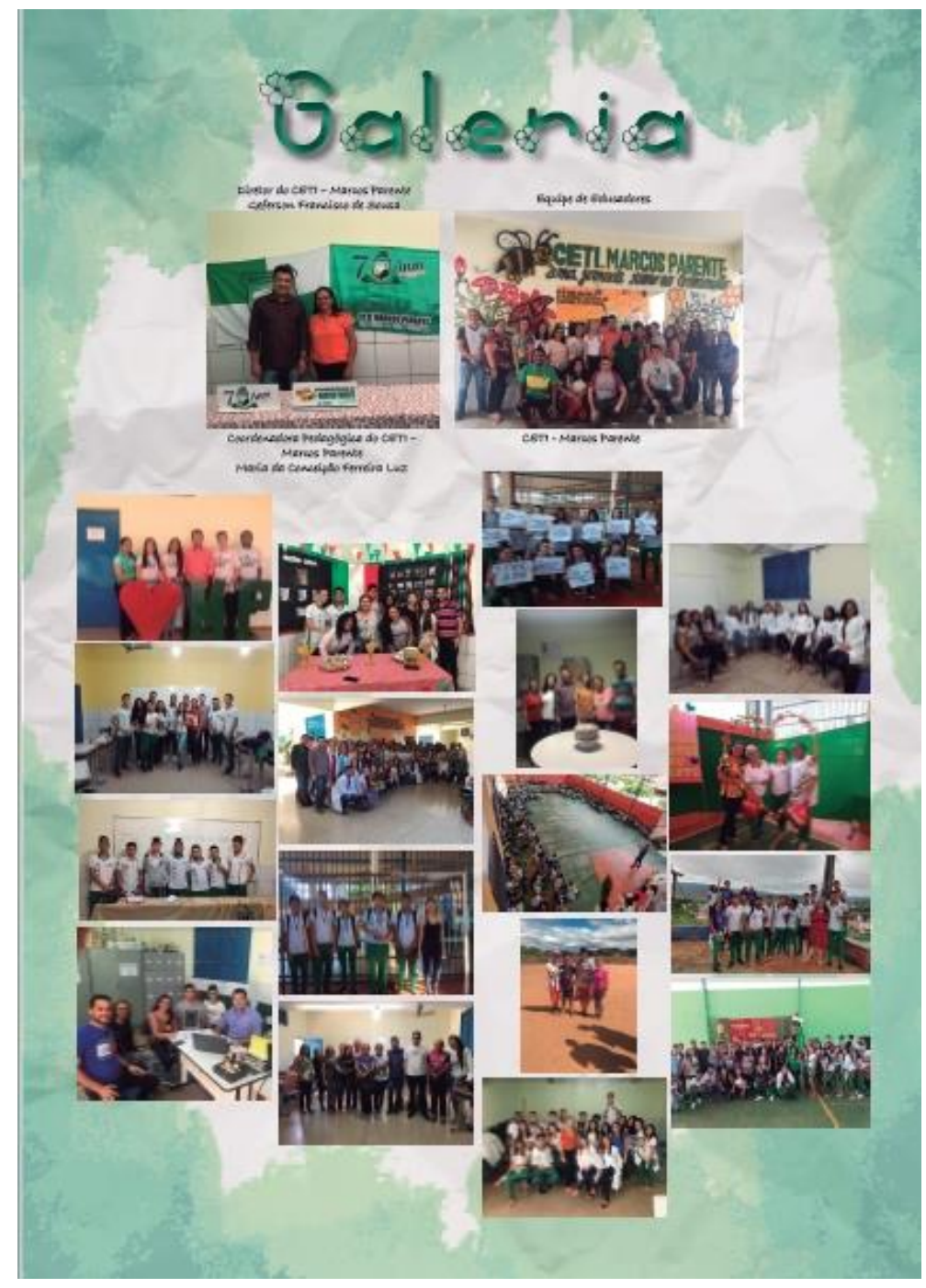

Fonte: Os autores (2019)

Por fim, a última página do jornal corresponde à Galeria, com a distribuição de fotografias de alguns dos momentos vivenciados na escola. $\mathrm{O}$ espaço funciona como uma espécie de cobertura dos principais acontecimentos do CETI Marcos Parente, que foram significativos para as experiências do alunado. Todas as fotos foram escolhidas pelos discente em conjunto com as equipes escolares e do PIBID.

O jornal produzido segue, portanto, a esquematização de um jornal impresso convencional. Contudo, estão presentes nele acontecimentos relativos ao cotidiano escolar dos alunos, de forma que essa produção funciona como instrumento de interação e comunicação de suas próprias vivências e como meio de tornar autênticas as suas identidades. 


\section{CONSIDERAÇÕES FINAIS}

Ao observarmos o desenvolvimento dos alunos na produção do Jornal do Conhecimento, aliados ao acompanhamento e aplicações de oficinas sobre os gêneros jornalísticos por parte das monitoras do Programa Institucional de Bolsa de Iniciação à Docência (PIBID), evidenciamos, a princípio, a importância da interação entre os discentes do Ensino Superior com os da Educação Básica.

As oficinas realizadas objetivaram levar aos alunos o conhecimento sobre os gêneros textuais da esfera jornalística, de modo a incentivá-los ao exercício da leitura e da produção de textos, assim como a observação e descrição, de forma organizada, das suas vivências no contexto educacional em que se encontravam.

Por meio dessas ações, foi produzido, editado e publicado um jornal escolar, elaborado, integralmente, pelos alunos da escola pública, ou seja, a atividade fez com que os alunos fossem os protagonistas nesse processo, de forma que o jornal impresso, de circulação estadual, por exemplo, não foi apenas levado ao ambiente escolar, mas confeccionado lá.

A nossa experiência, enquanto professores em formação inicial, foi proveitosa, tendo em vista que pudemos trabalhar gêneros textuais na escola, notadamente os da esfera jornalística e, ainda, pudemos refletir sobre as contribuições dessas atividades para o processo de ensino-aprendizagem dos alunos.

\section{REFERÊNCIAS}

BAKHTIN, M. Estética da criação verbal. 4. ed. São Paulo: M. Fontes, 2003.

BAZERMAN, C. Gêneros textuais, tipificação e interação. 2 ed. São Paulo: Cortez, 2006.

BOCCATO, V. R. C. Metodologia da pesquisa bibliográfica na área odontológica e o artigo científico como forma de comunicação. Revista de Odontologia da Universidade Cidade São Paulo, São Paulo, v. 18, n. 3, p. 265-274, 2006.

BRANDÃO, H. H. N.; MICHELETTI, G. Teoria e prática da leitura. In: Coletânea de textos didáticos. Componente curricular Leitura e elaboração de textos. Curso de Pedagogia em Serviço. Campina Grande: UEPB, 2002, p. 9.

BRASIL. Parâmetros Curriculares Nacionais: terceiro e quarto ciclos do ensino

fundamental: língua portuguesa. Secretaria de Educação Fundamental - Brasília: MEC/SEF, 1998. 
BRASIL. Parâmetros Curriculares Nacionais: Ensino Médio. Secretaria de Educação Fundamental - Brasília: MEC/SEF, 2000.

FARIA, M. A. O. Como usar o jornal na sala de aula. 10. ed, $1^{\text {a }}$ reimpressão. - São Paulo: Contexto, 2008.

FIORIN, J. L. (Org). Linguística? O que é isso? São Paulo: Contexto, 2013.

GAGLIARDI, E.; AMARAL, H. Escrevendo o Futuro: Olimpíadas da Língua Portuguesa. São Paulo: Cenpec, 2004.

LAGE, N. A estrutura da notícia. São Paulo: Editora Ática, 2005.

LAGE, N. Teoria e técnica de reportagem, entrevista e pesquisa jornalística. Rio de Janeiro. 2001. Disponível em: <http://nilsonlage.com.br/wp-content/uploads/2017/10/Areportagem.pdf $>$. Acesso em 11 de outubro de 2019.

MARCUSCHI, L. A. Gêneros textuais: definição e funcionalidade. In.: DIONÍSIO, A. P. Gêneros textuais e ensino. 4. ed. Rio de Janeiro: Lucerna, 2005, p. 31.

SCHNEUWLY, B.; DOLZ, J. Gêneros orais e escritos na escola. Tradução Roxane Rojo e Glais S. Cordeiro. Campinas: Mercado de Letras, 2004.

SILVA, Eduardo Dias da; SOUZA-DIAS, Romar; NASCIMENTO, Juscelino Francisco do. Language policies for the teaching of foreign language in public basic education in the Distrito Federal. Revista Com Censo: Estudos Educacionais do Distrito Federal, [S.1.], v. 6, n. 2, p. 22-33, mai. 2019. ISSN 2359-2494. Disponível em: <http://periodicos.se.df.gov.br/index.php/comcenso/article/view/623>. Acesso em: 02 mai. 2020.

TRAQUINA, N. Teorias do jornalismo: porque as notícias são como são. Florianópolis: Insular, 2 ed., 2005. 224p.

SWALES, J. Genreanalysis: English in academicandresearch settings. Cambridge: Cambridge University Press, p. 262, 1990. 